Jurnal Ilmiah Magister Agribisnis, 1(2) 2019:100-108,
Dol:

\title{
Analisis Faktor-Faktor yang Mempengaruhi Produksi Usahatani Nanas Pada Lahan Gambut di Kecamatan Panai Tengah Kabupaten Labuhanbatu
}

\section{Analysis of Factors Affecting Pineapple Farming Production On Peatlands in Panai Tengah District Labuhanbatu Regency}

\author{
Budi Rezky Setiawan'), Muhammad Buhari Sibuea ${ }^{2)}$, Erwin Pane ${ }^{3)}$
}

1) Program Studi Magister Agribisnis, Pascasarjana, Universitas Medan Area, Indonesia

2) Fakultas Pertanian, Universitas Muhammadiyah Sumatera Utara, Indonesia

3) Fakultas Pertanian, Universitas Medan Area, Indonesia

\begin{abstract}
Abstrak
Penelitian ini bertujuan untuk mengetahui bagaimana pengaruh luas lahan, jumlah bibit, jumlah tenaga kerja dan pupuk secara simultan dan parsial terhadap produksi nanas di kecamatan Panai Tengah Kabupaten Labuhanbatu. Penelitian ini di lakukan di Kecamatan Panai Tengah Kabupaten Labuhan Batu pada bulan April sampai Juni 2017. Penentuan lokasi dilakukan secara sengaja (purposive) dengan pertimbangan bahwa usahatani nanas di Kecamatan Panai Tengah merupakan usahatani yang dilakukan pada kondisi lahan dengan jenis tanah gambut dan hasil produksinya sudah memiliki ciri khas dengan sebutan nanas panai. Penelitian ini merupakan penelitian deskriptif dengan metode pendekatan kuantitatif. Jumlah sampel sebanyak 86 sampel. Data yang digunakan yaitu data primer dan sekunder. Data primer didapatkan dengan wawancara menggunakan kuesioner. Sedangkan data sekunder menggunakan data yang diperoleh dari instansi. Dalam penelitian ini langkah awal yang dilakukan adalah membentuk persamaan dengan fungsi Cobb Doughlas, kemudian persamaan tersebut ditransformasikan dalam bentuk logaritma natural untuk memudahkan analisis regresi berganda menggunakan program SPSS 19.0. Hasil penelitian menunjukkan bahwa faktor-faktor yang mempengaruhi produksi nanas adalah luas lahan, jumlah bibit, dan jumlah tenaga kerja.
\end{abstract}

Kata Kunci: buah, nanas, regresi

\begin{abstract}
This study aims to determine how the influence of land area, number of seedlings, the number of labor and fertilizer simultaneously and partially on pineapple production in Panai Tengah sub-district Labuhanbatu Regency. This research was conducted in the Central Panai District Labuhan Batu District in April to June 2017. Determination of the location was done intentionally (purposive) with the consideration that the pineapple farming in Central Panai District is a farm carried out on the condition of the land with peat soil types and the results of their production have been has a characteristic as panai pineapple. This research is a descriptive study with a quantitative approach. The number of samples was 86 samples. The data used are primary and secondary data. Primary data obtained by interview using a questionnaire. While secular data uses data obtained from the agency. In this research, the initial step taken is to form an equation with the Cobb Doughlas function, then the equation is transformed in the form of a natural logarithm to facilitate multiple regression analysis using the SPSS 19.0 program. The results showed that the factors affecting pineapple production were land area, number of seeds, and number of workers.
\end{abstract}

Keywords: fruit, pineapple, regression

How to Cite: Setiawan, B.R., M. B. Sibuea \& E. Pane. (2019). Analisis Faktor-Faktor yang Mempengaruhi Produksi Pertanian Nanas di Lahan Gambut di Kabupaten Panai Tengah, Kabupaten Labuhanbatu. Jurnal Ilmiah Magister Agribisnis, 1(2) 2019: 100-108,

*E-mail: erwinpane@staff.uma.ac.id ISSN 2550-1305 (Online)

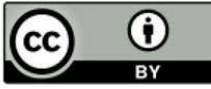




\section{PENDAHULUAN}

Tanaman Nanas merupakan salah satu komoditas hortikultura penting yang terus dikembangkan di Indonesia. Pada tahun 2015 produksi nenas Indonesia mencapai 1.729.603 ton, dan produksi nanas di Provinsi Sumatra Utara mencapai 223.128 ton.Untuk produksi nanas di Kabupaten Labuhan Batu tredapat di dua kecamatan, yaitu bilah hilir dengan produksi di tahun 2015 mencapai 6.000 ton, dan di Kecamatan Panai tengah produksi nanas mencapai 5.950 ton. Sejak pertama kali ditemukan oleh Columbus tanaman ini berkembang sangat cepat, tersebar ke seluruh dunia, terutama di daerah tropis, BPS (2015). Menurut Rosyidi dalam Faisal (2015) produksi adalah setiap usaha yang menciptakan atau memperbesar daya guna barang.

Buah nenas dapat dikonsumsi oleh masyarakat dengan cara dimakan langsung atau melalui proses lebih dahulu dengan cara dimasak atau dikalengkan. Alasan masyarakat menyukai buah nenas disamping untuk diet juga sebagai pemenuhan kebutuhan vitamin dan mineral bagi tubuh. Mulyohardjo (1984) menyebutkan adanya beberapa tipe nenas yang mempunyai nilai komersial yang tinggi, seperti : Spanish (berdaging putih), Queen (berdaging kuning) dan Cayenne (berdaging putih kekuningan). Nenas yang di kenal di Indonesia juga termasuk kedalam ketiga varietas tersebut, tetapi kebanyakan nenas dikenal atau disebut berdasarkan tempat tumbuhnya. Woentina (2015) meneliti tentang kelayakan usahatani di Desa Doda Kecamatan Kinovaro Kabupaten Sigi memperoleh bahwa usahatani yang dilakukan petani di Desa Doda Kecamatan Kinovaro Kabupaten Sigi layak untuk diusahaka dilihat dari jumlah produksi dan harga sesuai dengan harapan para petani dan memberikan keuntungan pada petani dalam mengusahatanikan nanas tersebut. Mustamir (2012), menganalisis peningkatan hasil tanaman nenas di lahan gambut yang bertujuan untuk mengetahui upaya yang dapat dilakukan dalam peningkatan produksi tanaman nenas dilahan gambut. Hasil penelitian menunjukkan bahwa takaran pemupukan pada perlakuan P2 (350 Kg Urea + $250 \mathrm{Kg} \mathrm{Sp}-$ $36+400 \mathrm{KgKCL}$ ) per ha merupakan upaya yang terbaik dalam peningkatan hasil tanaman nenas dilahan gambut.

Tanaman nenas banyak kegunaannya, antara lain mengandung vitamin $\mathrm{A}$ dan $\mathrm{C}$ sebagai antioksidan. Juga mengandung Kalsium, Fosfor, Magnesium, Besi, Natrium, Kalium, Dekstrosa, Sukrosa, dan Enzim Bromelain. Bromelain berkhasiat sebagai anti radang, membantu melunakkan makanan di lambung, serta menghambat pertumbuhan sel kanker. Kandungan seratnya dapat mempermudah buang air besar pada penderita sembelit. Tanaman nenas termasuk salah satu jenis tanaman yang sangat toleran terhadap tingkat keasaman yang tinggi yaitu $\mathrm{pH}$ antara 3 - 4. Gambut merupakan tanah yang terbentuk dari bahan organik pada fisiografi cekungan atau rawa, akumulasi bahan organik pada kondisi jenuh air, anaerob, menyebabkan proses perombakan bahan organik berjalan sangat lambat. Sehingga terjadi akumulasi bahan organik yang membentuk tanah gambut.

Di Kecamatan Panai Tengah, petani memanfaatkan lahan gambut untuk budidaya nanas. Lahan gambut yang ada di Kecamatan Panai Tengah merupakan gambut garaman yang berada diwilayah pantai, sehingga usahatani nanas di lahan gambut memiliki produksi yang tinggi di banding di lahan mineral (Rauf, 2015). Tipe penggunaan lahan 
gambut harus mengacu kepada kapabilitas dan kesesuaian lahan agar diperoleh hasil optimal dan berkelanjutan (Ratmini, 2012). Radjagukguk (2000) meneliti tentang perubahan sifat-sifat fisik dan kimia tanah gambut akibat reklamasi lahan gambut untuk pertanian memperoleh hasil yang menyatakan bahwa lahan-lahan gambut tropika terutama di indonesia telah lama diusahakan sebagai lahan pertanian oleh penduduk lokal dan belakangan ini perluasan pertanian kelahan-lahan gambut kebutuhan akan pangan dan produk tanaman perkebunan.

Lahan gambut di panai tengah sudah lama dibudidayakan oleh petani setempat, baru pada tahun 2010 budidaya nanas ini di kelola oleh Pemerintah Daerah Labuhan Batu se bagai komoditas nanas yang bisa di andalkan di Kecamatan Panai Tengah.Rendahnya produksi dan produktivitas nanas menyebabkan terjadinya ketidak seimbangan antara produksi dan permintaan. Hal ini memerlukan perhatian yang sangat serius dalam pengembangan usaha tani nanas lahan gambut di Kecamatan Panai Tengah, oleh karena itu penulis tertarik melakukan penelitian yang menganalisis faktor-faktor yang mempengaruhi produksi usahatani nanas pada lahan gambut di Kecamatan Panai Tengah, Kabupaten Labuhan Batu. Oleh karena itu dalam penelitian ini bertujuan untuk mengetahui bagaimana pengaruh luas lahan, jumlah bibit, jumlah tenaga kerja dan pupuk secara simultan dan parsial terhadap produksi nanas di kecamatan Panai Tengah Kabupaten Labuhanbatu.

\section{METODE PENELITIAN}

Penelitian ini di lakukan di Kecamatan Panai Tengah Kabupaten Labuhan Batu pada bulan April sampai Juni 2017. Penentuan lokasi dilakukan secara sengaja (purposive) dengan pertimbangan bahwa usahatani nanas di Kecamatan Panai Tengah merupakan usahatani yang dilakukan pada kondisi lahan dengan jenis tanah gambut dan hasil produksinya sudah memiliki ciri khas dengan sebutan nanas panai. Penelitian ini merupakan penelitian deskriptif dengan metode pendekatan kuantitatif. Jumlah sampel sebanyak 86 sampel. Data yang digunakan yaitu data primer dan sekunder. Data primer didapatkan dengan wawancara menggunakan kuesioner. Sedangkan data sekumder menggunakan data yang diperoleh dari instansi.

Dalam penelitian ini langkah awal yang dilakukan adalah membentuk persamaan dengan fungsi Cobb Doughlas, kemudian persamaan tersebut ditransformasikan dalam bentuk logaritma natural untuk memudahkan analisis regresi berganda menggunakan program SPSS 19.0.Bentuk persamaan dengan fungsi cobb doughlas sebagai berikut :

$\mathrm{Y}={ }^{\beta} 0 . \mathrm{X} 1^{\beta} 1 \mathrm{X} 2^{\beta} 2 \mathrm{X} 2^{\beta} 3 \mathrm{X} 3^{\beta} 3 \mathrm{X} 4^{\beta} 4 \mathrm{e}$ (Soekartawi, 2002)

Keterangan :

Y : Jumlah Poduksi Nanas (Buah)

X1 : Luas lahan (Hektar)

$\mathrm{X} 2$ : Jumlah bibit (Bibit)

X3 : Jumlah tenaga kerja (Orang)

X4 : Jumlah pupuk (Kilogram)

${ }^{\beta_{0}} \quad$ : Konstanta

${ }^{\beta} 1,{ }^{\beta} 5$ : Koefisienregresi 
e : Error

Kemudian untuk melakukan analisis digunakan persamaan sebagai berikut :

$\operatorname{Ln} Y={ }^{\beta} 0+{ }^{\beta} 1 \operatorname{LnX} 1+{ }^{\beta} 2 \operatorname{LnX} 2+{ }^{\beta} 3 \operatorname{LnX} 3+{ }^{\beta} 4 \operatorname{LnX} 4+e$

Dari hasil estimasi regresi berganda yang diperoleh, dilakukan interprestasi untuk mengetahui bagaimana pengaruh dari masing-masing variabel.

\section{HASIL DAN PEMBAHASAN}

Untuk mengetahui pengaruh dari variabel bebas antara lain luas lahan, jumlah bibit, jumlah tenaga kerja dan pupuk sebagai faktor-faktor yang mempengaruhi variabel terikat yaitu produksi nanas di Kecamatan Panai Tengah dilakukan dengan membentuk fungsi Cobb Doughlas kemudian persamaan tersebut dianalisis dengan persamaan regresi berganda dalam menggunakan model regresi berganda dalam bentuk Logaritma natural (Ln) dengan menggunakan bantuan komputer program SPSS 16.0,dapat dilihat pada table 1. Model dalam penelitian ini sudah lolos uji asumsi klasik sehingga model dalam penelitian diasumsikan model terbaik.

Tabel 1. Hasil estimasi regresi berganda dengan program SPSS 19.0

\begin{tabular}{ccccccc}
\hline Variable & $\begin{array}{c}\text { Unstandardized } \\
\text { Coefisien }\end{array}$ & t-statistic & Sig. T & F-stat & Sig. F & R-Squared \\
\hline Contant & 2,695 & 4,614 & 0,00 & 150,875 & 0,00 & 0,882 \\
X1 (Luas lahan) & 0,363 & 5,045 & 0,00 & & Atau \\
X2 (Bibit) & 0,484 & 7,894 & 0,00 & & $88,20 \%$ \\
X3 (Tenaga Kerja) & 0,289 & 4,706 & 0,00 & & \\
X4 (Pupuk) & $-0,005$ & 0,128 & 0,89 & & & \\
\hline
\end{tabular}

Sumber : Analisis data Primer (diolah), 2017

Bentuk persamaan fungsi Cobb Doughlas yang terbentuk dari hasil analisis pada tabel 1 dapat dilihat pada persamaan (1).

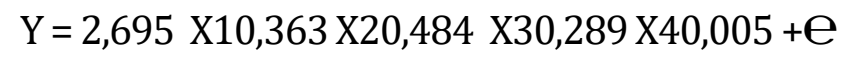

Kemudian persamaan tersebut ditransformasikan dalam bentuk logaritma natural dapat dilihat pada ersamaan (2).

$$
\operatorname{Ln} Y=\beta 0+\beta 1 \operatorname{LnX} 1+\beta 2 \operatorname{LnX} 2+\beta 3 \operatorname{LnX} 3-\beta 4 \operatorname{LnX} 4+\mathrm{e}
$$

Hasil persamaan regresi dalam bentuk logaritma natural dapat dilihat pada persamaan (3).

$$
\operatorname{Ln} Y=2,695+0,363 \operatorname{LnX} 1+0,484 \operatorname{LnX} 2+0,289 \operatorname{LnX} 3-0,005 \operatorname{LnX} 4+\mathrm{e} \text { (3). }
$$

Untuk interprestasi hasil analisis regresi diatas menggunakan persamaan fungsi Cobb Doughlas, namun nilai konstanta dikembalikan kedalam bentuk antilog, dapat dilihat pada persamaan (4).

$$
\mathrm{Y}=495,45 \mathrm{X10,363} \text { X20,484 X30,289 X40,005 +e }
$$

Dari tabel 1 dan persamaan (4) dapat dilihat bahwa persamaan regresi dalam bentuk logaritma natural memiliki makna sebagai berikut : 
Setiawan, B.R., M. B. Sibuea \& E. Pane. Analisis Faktor-Faktor yang Mempengaruhi Produksi Pertanian Nanas di Lahan Gambut di Kabupaten Panai Tengah, Kabupaten Labuhanbatu.

a. Nilai Konstanta

Nilai konstanta pada persamaan Cobb Douglassetelah di antilog kan sebesar 495,45 menjelaskan bahwa variabel X1 sampai dengan X4 memiliki pengaruh sebesar 495,45 terhadap hasil produksi nanas, dan dari fungsi tersebut menyatakan bahwa faktor produksi yang dimasukkan dalam model penelitian tergolong elastis dihitung dari nilai koefisien yang lebih besar dari 1.

$\beta 1+\beta 2+\beta 3+\beta 4=1,131>1$. Elastis ( increasing return to scale)

artinya, apabila terjadi penambahan faktor produksi akan menghasilkan tambahan produksi yang lebih besar juga. Jika fakor produksi ditambah sebesar 10\%, maka produksinya akan bertambah sebesar 20\%. (Soekartawi, 2002).

b. Nilai Variabel X1 (Luas Lahan)

Nilai koefisien variabel X1 (Luas Lahan) sebesar 0,363. Tanda positif pada variabel tersebut memberikan arti adanya pengaruh positif dan signifikan terhadap hasil produksi nanas di kecamatan Panai Tengah Kabupaten Labuhanbatu. Hasil penelitian ini berarti bila luas lahan meningkat 1 satuan, maka hasil produksi nanas akan meningkat 0,3 kali. Hal ini menunjukkan bahwa luas lahan yang digunakan petani untuk mengusahakan tanaman nanas sangat berpotensi dalam meningkatkan hasil produksi.Tanaman nenas sangat rentan dengan kondisi perairan di tanah, atau dengan kata lain tanaman nenas sangat sensitif terhadap stress air. Kondisi perairan di tanah gambut cukup stabil, sebab unsur hara yang terkandung pada tanah gambut berasal dari pelapukan bahan organik dan kondisi tanahnya cukup lembab. Kondisi tanah gambut yang terdapat pada lokasi penelitian merupakan tanah gambut dengan kedalaman 50-200 cm dari permukaan tanah. Produktifitas nenas di lokasi penelitian ini dengan kondisi tanah gambut tersebut lebih tinggi dibandingkan produktifitas nenas yang diusahakan di lahan jenis tanah mineral. Terlihat dari jenis bobot buah yang lebih besar, karena sumber nutrisi tanaman banyak terdapat pada tanah gambut yang memiliki unsur hara tinggi dari bahan organik, yang sangat cocok untuk pertumbuhan tanaman nenas.

c. Nilai Variabel X2 (Jumlah Bibit)

Nilai variabel X2 (Jumlah Bibit) sebesar 0,484. Tanda positif tersebut memberikan arti bahwa adanya pengaruh positif dan signifikan terhadap hasil produksi nanas di kecamatan Panai Tengah Kabupaten Labuhanbatu. Hasil penelitian ini berarti bila jumlah bibit yang digunakan meningkat 1 satuan, maka hasil produksi nanas juga akan meningkat 0,4 kali. Hal ini menunjukkan bahwa jumlah bibit sangat berperan penting dalam peningkatan hasil produksi nanas. Jumlah bibit nenas pada lahan gambut lebih banyak dibandingkan dengan tanaman nenas di lahan mineral. Karena jarak tanam yang digunakan petani pada lahan gambut lebih rapat. Jarak tanam tanaman nenas di lahan gambut yaitu $60 \mathrm{~cm}$ x $60 \mathrm{~cm}$. Sedangkan di lahan mineral jarak tanam yang digunakan $60 \mathrm{~cm} \times 150 \mathrm{~cm}$.

d. Nilai Variabel X3 (Jumlah Tenaga Kerja)

Nilai variabel X3 (Jumlah Tenaga Kerja) sebesar 0,289. Tanda positif pada koefisien tersebut memberikan arti bahwa adanya pengaruh positif dan signifikan terhadap hasil produksi nanas di kecamatan Panai Tengah Kabupaten Labuhanbatu. Hasil penelitian ini berarti bila jumlah tenaga kerja meningkat 1 satuan, maka hasil produksi nanas juga akan meningkat 0,2 kali. Hal ini menunjukkan bahwa penggunaan tenaga kerja yang meningkat memberikan kontribusi yang baik dalam pengelolaan tanaman nanas tersebut. 
Peningkatan jumlah tenaga kerja pada usahatani tanaman nenas,akan meningkatkan produksi nenas per hektar. Penggunaan tenaga kerja yang dimanfaatkan untuk melakukan prosen penanaman, pemupukan, pemeliharaan gulma dan juga panen, sangat mendukung peningkatan hasil produksi nenas tersebut. Pada kondisi lahan gambut dalam penelitian ini, usahatani nenas sangat membutuhkan tenaga kerja yang banyak dalam bidang perawatan atau pemeliharaan. Sebab dengan kondisi tanah gambut tersebut, diperlukan perhatian extra dalam perawatan tanaman yang tumbuh tidak baik atau pertumbuhan miring. Pemeliharaan juga dilakukan untuk penyisipan tanaman yang mati atau rusak. Kebutuhan tenaga kerja tersebut lebih banyak pada kondisi lahan gambut dibandingkan pada lahan mineral.

e. Nilai Variabel X4 (Jumlah Pupuk)

Nilai variabel X3 (Jumlah Pupuk) sebesar -0,005. Tanda koefisien negatif tersebut memberikan arti bahwa terdapat pengaruh negatif dan tidak signifikan terhadap hasil produksi nanas di kecamatan Panai Tengah Kabupaten Labuhanbatu. Hasil penelitian ini berarti bila jumlah meningkat 1 satuan, maka terjadi penurunan produksi sebanyak 0,005 kali. Pemberian pupuk sampai pada tahap maksimum, sehingga bila pupuk diberikan berlebih maka akan terjadi penurunan produksi.

Pemberian pupuk pada tanaman nenas yang dilakukan di lokasi penelitian dengan kondisi tanah gambut lebih banyak menggunakan pupuk abu. Penggunaan pupuk abu tersebut mudah diperoleh petani di daerah penelitian. Presepsi petani yang mengusahakan tanaman nenas dilokasi penelitian tersebut, disebabkan kondisi tanah yang digunakan untuk usahatani nenas adalah tanah gambut yang memiliki unsur hara tinggi dari bahan organik, maka cukup menggunakan pupuk abu saja, sedangkan kebutuhan nutrisi tanaman nenas tidak cukup hanya dengan pemberian pupuk abu. Oleh karena itu, semakin banyak pupuk abu yang digunakan petani untuk tanaman nenas di lokasi penelitian tidak memberikan peningkatan produksi nenas, melainkan dapat menurunkan produksinya.

Pada lahan gambut pemberian pupuk harus tepat untuk mangatasi masalah keasaman tanah gambut, pupuk abu yang digunakan petani berpengaruh untuk menurunkan keasaman tanah, dan selanjutunya harus dilakukan pemberian unsur hara dari jenis pupuk lain agar nutrisi tanaman terpenuhi. unsur hara yang umumnya perlu di tambahkan dalam bentuk pupuk adalah N, P, K, Ca, Mg serta sejumlah unsur hara mikro yang utama $\mathrm{Cu}, \mathrm{Zn}$, dan Mo. Pemberian $\mathrm{Cu}$ diduga lebih efektif, karena sifat sematannya yang sangat kuat pada gambut. Berbeda dengan perlakukan pada lahan mineral, pupuk extra yang digunakan yaitu pupuk kandang, dan tetap memberikan kebutuhan nutrisi tanaman dengan pupuk majemuk lainnya seperti NPK, Urea dan SP36.

Koefisien Determinasi

Pengujian koefisien determinasi (R2) digunakan untuk mengukur proporsi atau persentase kemampuan model penelitian dalam menerangkan variabel terikat (variabel Y). Koefisien determinasi berkisar antara nol sampai dengan satu $(0 \leq \mathrm{R} 2 \leq 1)$. Jika R2 semakin besar mendekati satu, maka dapat dikatakan bahwa pengaruh variabel bebas (X) adalah besar terhadap variabel terikat (Y). Hal ini berarti model yang digunakan semakin kuat untuk menerangkan pengaruh variabel bebas terhadap variabel terikat, demikian sebaliknya.

Dari hasil regresidiperoleh nilai $\mathrm{R}^{2}$ sebesar 0,882 . Hal ini menjelaskan bahwa variabelvariabel bebasdiantaranya variabel luas lahan, jumlah bibit, jumlah tenaga kerja dan jumlah 
Setiawan, B.R., M. B. Sibuea \& E. Pane. Analisis Faktor-Faktor yang Mempengaruhi Produksi Pertanian Nanas di Lahan Gambut di Kabupaten Panai Tengah, Kabupaten Labuhanbatu.

pupuk yang dimasukkan dalam modelpenelitian memberi penjelasan mengenai variabel terikat yaitu jumlah produksi nanas sebesar 88,20\%. Sedangkan sisanya sebesar 11,8\% lagi dijelaskan oleh variabel lain yang tidak dimasukkan dalam model penelitian.

Pengujian secara simultan (Uji F)

Pengujian secara simultan digunakan untuk menujukkan apakah keseluruhan variabel bebas berpengaruh terhadap variabel terikat. Nilai F statistik menunjukkan bahwa secara simultan atau secara serempak pengaruh variabel bebas diantaranya variabel luas lahan, jumlah bibit, jumlah tenaga kerja dan jumlah pupuk secara positif dan signifikan terhadap variabel terikat yaitu jumlah produksi nanas.

Berdasarkan hasil uji simultan atau secara serempak dari hasil estimasi tabel diatas menunjukkan bahwa model regresi ini memiliki nilai F hitung atau F statistik sebesar150,875, yang signifikan pada derajat kepercayaan 95\% dilihat dari perbandingan nilai signifikan $\mathrm{F}$ statistik sebesar 0,00 lebih kecil dari alpa 0,05. Hal ini menjelaskan bahwaluas lahan, jumlah bibit, jumlah tenaga kerja dan jumlah pupuk secara bersama-sama memberikan pengaruh yang positif dan signifikan terhadap hasil produksi nanas.

Pengujian Secara Parsial (Uji t)

Berdasarkan hasil perhitungan analisis regresi yang telah diperoleh, terlihat adanya nilai t statistisk dan nilai signifikan t statistik dari variabel luas lahan (X1), bibit (X2), dan Tenaga kerja (X3), dan Pupuk (X4). Nilai signifikan t statistik pada variabel X1 (Luas lahan) diperoleh sebesar 0,00 lebih kecil dari alpa 0,05 yang menyatakan bahwa variabel luas lahan memiliki pengaruh signifikan terhadap jumlah produksi nanas di Kecamatan Panai Tengah Kabupaten Labuhanbatu. Luas lahan yang digunakan petani dalam usahatani nanas di Kecamatan Panai Tengah tidak luas. Para petani hanya memanfaatkan halaman rumah dan kebun yang dekat dengan tempat tinggalnya. Berdasarkan hasil analisa regresi, luas lahan tersebut berpengaruh positif dan signifikan terhadap hasil produksi nanas. Oleh sebab itu, bagi para petani yang memiliki lahan yang luas digunakan untuk usahatani nanas, maka hasil produksi nanasnya juga tinggi. Petani yang mengusahatanikan tanaman nanas di Kecamatan Panai tengah ini belum ada yang melakukan usahataninya dalam skala luas dengan pemanfaatan lahan yang luas, sebab sistem usahatani yang dilakukan oleh petani didaerah penelitian tersebut bukan merupakan mata pencaharian pokok, dikarenakan petani juga bekerja dibidang lain seperti menjadi karyawan pabrik kelapa sawit yang ada di lokasi Kecamatan Panai Tengah dan juga ada yang bekerja sebagai wiraswasta lainnya. Dan usahatani nanas dilakukan oleh petani tersebut pada saat sudah kembali dari pekerjaan mereka. Oleh karena itu petani tidak memfokuskan pekerjaannya dibidang usahatani nanas saja, dengan demikian usahatani nanas hanya dilakukan dengan memanfaatkan lahan dengan skala kecil atau memanfaatkan pekarangan rumah

Nilai signifikan t statistik pada variabel X2 (jumlah bibit) adalah 0,00 lebih kecil dari alpa 0,05 yang menyatakan bahwa variabel jumlah bibit memiliki pengaruh signifikan terhadap jumlah produksi nanas di Kecamatan Panai Tengah Kabupaten Labuhanbatu. Jumlah bibit memiliki pengaruh positif dan signifikan terhadap perolehan hasil produksi nanas di Kecamatan Panai Tengah. Jumlah produksi yang diperoleh dalam usahatani nanas tergantung pada banyaknya jumlah bibit yang ditanam. Sebab diketahui dalam 1 bibit yang ditanam akan menghasilkan 1 buah nanas dalam periode 1 kali masa panen. Bibit yang digunakan dalam usahatani ini seperti yang telah dijelaskan sebelumnya bahwa menggunakan bibit yang berasal 
dari tunas anakan. Tunas anakan diperoleh dari tanaman nanas yang sudah tua dan banyak mengeluarkan tunas baru disekitar tanaman utamanya. Kecamatan Panai Tengah memiliki banyak lahan yang kondisi tanaman nanasnya sudah tua, dari hasil usahatani nanas petani pada periode sebelumnya. Dengan demikian perolehan bibit nanas di daerah penelitian ini sangat mudah dan tidak mengeluarkan biaya yang banyak untuk memperoleh bibit nanas tersebut.

Nilai signifikan t statistik pada variabel X3 jumlah tenaga kerja sebesar 0,00 dan lebih kecil dari alpa 0,05 yang menyatakan bahwa variabel jumlah tenaga kerja memiliki pengaruh signifikan terhadap jumlah produksi nanas di Kecamatan Panai Tengah Kabupaten Labuhanbatu. Dari hasil perhitungan regresi tersebut dapat dilihat bahwa pengaruh jumlah tenaga kerja berpengaruh signifikanbaik terhadap perolehan hasil produksi nanas. Dapat disimpulkan bahwa dalam melakukan usahatani nanas, tenaga kerja yang banyak digunakan dan efisien akan menghasilkan jumlah produksi nanas yang baik. Karena tanaman nanas tersebut sangat membutuhkan perhatian dan perlakuan khusus dari pelaku usahataninya. Sedemikian diketahui bahwa tanaman nanas perlu dilakukan penyiangan dari gulma penganggu yang dapat menghambat pertumbuhan nanas tersebut, dan juga dari kondisi bentuk tumbuh yang sangat rentan akibat angin ataupun perairan di kondisi lahan gambut seperti di Kecamatan Panai Tengah. Tenaga kerja yang digunakan dalam proses usahatani nanas ini diperoleh dari tenaga kerja dalam keluarga. Petani yang memiliki lahan usahatani nanas bekerja langsung dalam usahataninya tersebut, dan dibantu oleh anggota keluarga. Namun ada juga petani yang menggunakan tenaga kerja dari luar keluarga, dikarenakan banyaknya pekerjaan yang akan dilakukan dalam proses usahatani tersebut. Dengan demikian usahatani nanas yang dilakukan dapat menghasilkkan tanaman yang tumbuh dengan baik sehingga menghasilkan produksi nanas yang sesuai jumlah dengan harapan petani nanas tersebut. Semakin banyak tenaga kerja yang digunakan, perawatan tanaman nanas lebih efektif dan menghasilkan produksi yang maksimal.

Nilai signifikan t statistik pada variabel X4 jumlah pupuk sebesar 0,89 dan lebih besar dari alpa 0,05 yang menyatakan bahwa variabel jumlah pupuktidak memiliki pengaruhyang signifikan terhadap jumlah produksi nanas di Kecamatan Panai Tengah Kabupaten Labuhanbatu. Jumlah pupuk memiliki pengaruh negatif dan tidak signifikan terhadap hasil produksi nanas. Usahatani yang dilakukan di Kecamatan Panai Tengah merupakan usahatani yang dilakukan pada jenis tanah gambut, dimana jenis tanah tersebut merupakan tanah yang sudah banyak mengandung zat ataupun unsur hara yang dibutuhkan tanaman disebabkan unsur pembentuk tanah gambut tersebut adalah hasil pelapukan tanaman organik sebelumnya.Dengan demikian, pemanfaat lahan gambut tidak membutuhkan lagi banyak pupuk dari luar, seperti pupuk abu yang digunakan petani dalam usahatani nanas tersebut. Semakin banyak penggunaan pupuk abu juga tidak memiliki pengaruh terhadap hasil produksinya, bahkan akan menurunkan jumlah prduksi. Maka sebaiknya petani nanas di Kecamatan Panai Tengah lebih banyak menggunakan modalnya untuk faktor produksi lain seperti penambahan jumlah bibit atau luas lahan dan tenaga kerja yang lebih berpotensi untuk meningkatkan hasil produksi dibandingkan penggunaan pupuk abu tersebut.

\section{SIMPULAN}


Setiawan, B.R., M. B. Sibuea \& E. Pane. Analisis Faktor-Faktor yang Mempengaruhi Produksi Pertanian Nanas di Lahan Gambut di Kabupaten Panai Tengah, Kabupaten Labuhanbatu.

Dari hasil analisis dapat ditarik beberapa kesimpulan bahwa secara simultan atau secara serempak menunjukkan bahwa variabel bebas diantaranya variabel luas lahan, jumlah bibit, jumlah tenaga kerja, dan jumlah pupuk berpengaruh terhadap produksi nanas di Kecamatan Panai Tengah. Secara partial atau secara serempak variabel bebas luas lahan, jumlah bibit, dan jumlah tenaga kerja berpengaruh nyata dan signifikan terhadap produksi nanas di Kecamatan Panai Tengah Kabupaten Labuhanbatu. Secara partial variabel jumlah pupuk tidak berpengaruh nyata dan signifikan terhadap produksi nanas di Kecamatan Panai Tengah Kabupaten Labuhanbatu. Penggunaan pupuk dalam hal ini yang digunakan adalah jenis pupuk abu, semakin banyak pupuk abu yang digunakan dalam usahatani tidak memberikan pengaruh dalam hal peningkatan produksi nanas. Para petani diharapkan dapat meningkatkan penggunaan luas lahan, jumlah bibit, tenaga kerja dan juga penggunaan pupuk dengan jenis pupuk yang mengandung unsur NPK. Untuk penelitian selanjutnya diharapkan peneliti melakukan penelitian yang menganalisis tentang efektifitas penyuluhan terhadap petani nanas, kelayakan usahatani nanas, jalur pemasaran, sumbangan terhadap ekonomi dan pendapatan daerah kecamatan Panai Tengah Kabuaten Labuhanbatu tersebut

\section{DAFTAR PUSTAKA}

BPS. (2015). Kecamatan Panai Tengah Dalam Angka tahun 2015. Badan Pusat Statistik Provinsi Sumatera Utara. BPS. (2016). Kecamatan Panai Tengah Dalam Angka tahun 2015. Badan Pusat Statistik Provinsi Sumatera Utara. Faisal, Floperda A.W. (2015). Analisis Pendapatan Usahatani Jeruk Siam. Jurnal Ilmu Administrasi Bisnis. ISSN 2355-5408. Vol. 3, No3, 2015: 600-611.

Mulyohardjo, M. (1984). Nenas dan Teknologi Pengolahannya. Liberty, Yogyakarta.

Mustamir, Elly. (2012). Upaya Peningkatan Hasil Tanaman Nenas Di Lahan Gambut. Jurnal Program Studi Agroekoteknologi Fakultas Pertanian Universitas Tanjungpura. Pontianak.

Rajagukguk, B. (2000). Perubahan Sifat-sifat fisik dan Kimia Tanah Gambut Akibat Reklamasi Lahan Gambut Untuk Pertanian. Jurnal Ilmu Tanah dan Lingkungan 2000, II(1).

Ratmini. Sri,Npp. (2012). Karakteristik dan Pengelolaan Lahan Gambut untuk Pengembangan Pertanian. Jurnal Lahan Suboptimal. ISSN:2252-6188(Print), ISSN:2302-3015 (Online) Vol.1, No. 2: 197-206, Oktober 2012.

Rauf, A. (2015). Optimalisasi Lahan Gambut Untuk Perkebunan Kelapa Sawit. http://stiper-labuhanbatuac.id/prof-ir-abdul-rauf-mp-optimalisasi-lahan-gambut-untu-perkebunan-kelapa sawit. Diakses tanggal 11 Desember 2015.

Soekartawi. (2002). Teori Ekonomi Produksi dengan Pokok Bahasan Analisis Fungsi Cobb-Douglas. Rajawali Press, Jakarta.

Woentina, K. (2015). Analisis Kelayakan Usahatani Nanas di Desa Doda Kecamatan Kinovaro Kabupaten Sigi. E-J Agrotekbis 3(2) : 240-246, April 2015. 